such use of the Red Cross, not connected with the National Society, that may come within their cognizance. The Society has a list of those manufacturers who obtained the Red Cross, as a trademark previous to its reincorporation under the present charter in January, 1905. It should be the duty of every American to see to it that in our country this Red Cross insignia, created for so beneficient a purpose, is protected as far as possible from the degradation of becoming a mere advertisement for money making designs.

\title{
DISCHARGED PATIENTS BEFRIENDED
}

The Directors of Bellevue Hospital have done a very fine thing. They have engaged a graduate nurse to look after and befriend all patients who are discharged from the hospital, so that hereafter no patient can leave the hospital homeless and without resource. Miss Wadley, who is eminently fitted for this post, has been appointed. She has her office in the hospital, and goes about in the wards, learning which patients are due to be discharged, and then finding out whether they have friends or homes to go to. If not, it is her duty to make some provision for them, either by putting them in charge of some charitable society or sending them to Homes or Shelters, or in some way to befriend them. Miss Wadley finds the work most gratifying and will be able to do an immense amount of good.

\section{THE ORANGE TRAINING-SCHOOL}

$W_{E}$ have noted in a previous number the taking over of the training-school at Orange, N. J., by the hospital. We understand that this readjustment has been brought about with great harmony, and that the course is to be extended to three years, including a preparatory course, the extern duty being in time curtailed. The reason for the giving up the Orange school as a separate institution was because of its inability to meet the requirements of registration of the New York law, and the close proximity of Orange to New York City made the lack of such registration a serious drawback to the graduates, reacting upon the school by making it almost impossible to obtain probationers.

We understand that a school for attendance is to be started in the autumn by a number of the ladies on the Board who are not thoroughly in accord with the new arrangements.

\section{THE NEW OWNERSHIP OF THE BRITISH JOURNAL}

The announcement made by Miss Dock in the foreign department, of the taking over of the British Journal of Nursing by the organized 
nurses of Great Britain, is a matter for professional rejoicing everywhere. This is an indication of splendid unity among the progressive and intelligent nurses of Great Britain, and it perpetuates the life work of Mrs. Bedford Fenwick and endorses the principles for which she has struggled single-handed so many years. We congratulate Mrs. Fenwick for this splendid recognition of her work, and we join hands with the nurses of Great Britain who have so valiantly rallied to her support.

\section{THE JOURNAL YEAR}

With this issue the sixth year of the Journal's life closes; to an outsider, perhaps, a year of uneventful success, but to those within the circle the most prosperous and professionally influential since it has been established. To those who are specially interested in the Journal's welfare, we want to say that the greatest need which presents itself to the editor at this time, is to increase the number of pages in each issue. We profess to give sixty-four pages of reading matter, for a $\$ 2.00$ subscription. We give, more often, seventy-two or eighty pages, and our ambition is to print ninety-six pages in each number, in order that we may use every item of material that presents itself for our consideration. From a business standpoint, to so increase the number of pages, without increasing the subscription price, would be the extreme of bad management, and we might expect disaster in consequence. If, however, the great group of organizations which are interested in the JourNaL's success would concentrate their forces for a few months upon the subject of doubling the subscription list, the increase in the number of pages could be made with perfect safety. Each individual subscriber who will send a new subscription with her own renewal, will receive a copy of Miss McIsaac's "A New Cranford." Each alumnæ association which will secure all of its members as subscribers, will be furnished the JournaL at a club rate of $\$ 1.50$.

The past year has added greatly to the value of the Journal to the private nurses. We have a splendid group of papers on hand, and so many promised that we can speak positively in regard to the quality of the material which we shall present in the near future. Among the papers on hand, we have "Nursing in Old Mexico," by Olive Purves; "Disposal of Sputa," Edith P Jones; "Training for Visiting Nursing," and "Rural Nursing," L. L. Dock; "Artistic Nursing," Mary F. Sewell; "Nursing Treatment of Infantile Diarrhœa," Miss Goodwin; "A Typhoid Case," Miss Needham; "Preparation for an 